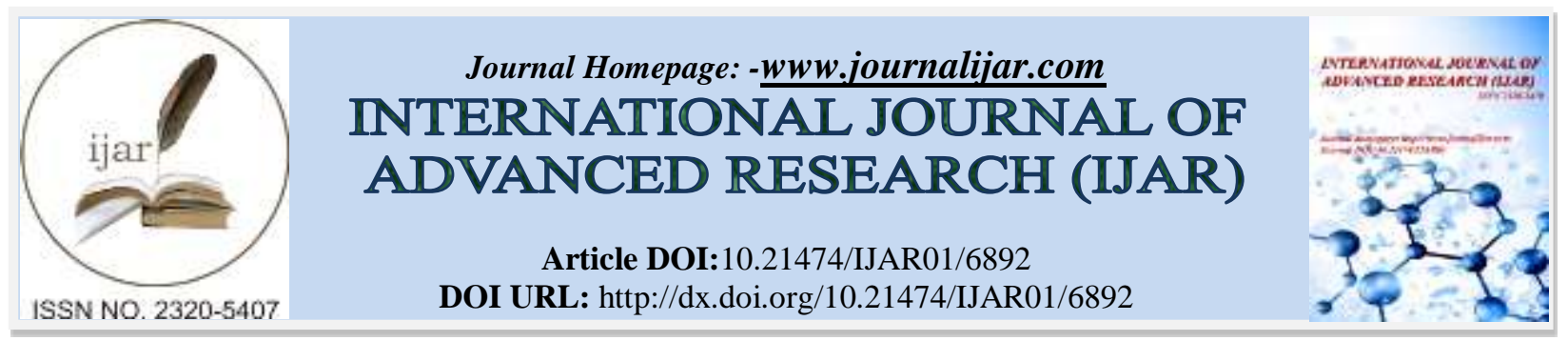

RESEARCH ARTICLE

\title{
SONOGRAPHIC FINDINGS IN PATIENTS WITH LOWER LIMB SWELLING, SEEN AT MOI TEACHING AND REFERRAL HOSPITAL, ELDORET, KENYA.
}

\section{Ochako Agnes, Abuya Joseph* and G. D. Onditi Elias.}

1. Resident, Department of Radiology and Imaging School of Medicine, Moi University

2. Senior Lecturer, Department of Radiology and Imaging, P. O. Box 4606-30100, Eldoret-Kenya School of Medicine, Moi University, Kenya.

3. Associate Professor and Head, Department of Radiology and Imaging, School of Medicine, Moi University, Kenya.

\section{Manuscript Info}

\section{Manuscript History}

Received: 09 February 2018

Final Accepted: 11 March 2018

Published: April 2018

\section{Keywords:-}

Lower limb swelling, Deep Venous Thrombosis, Sonography, Moi Teaching and Referral Hospital.

\section{Abstract}

Background: Imaging modalities in lower limb swelling play a major role in identifying various pathologies that have significant impact in clinical outcomes. Ultrasonography has been shown to have comparable outcome with advanced techniques like Magnetic Resonance Imaging (MRI) in soft tissue imaging and it is real time and fairly non-invasive.

Objectives: To evaluate clinical findings and describe patterns of sonographic findings in lower limb swelling at Moi Teaching and Referral Hospital (MTRH) Eldoret, Kenya.

Methods: This was a cross sectional study done in the MTRH, Radiology and Imaging Department. Using purposive sampling, 109 patients were recruited. 4 declined consent while 2 withdrew. Data was analyzed using STATA version 10. Descriptive statistics were used for continuous variables while frequency listings were used for categorical variables. Chi square test was used to assess associations between categorical variables.

Results: Their median age was 41 years and the majority were women 67(65\%). The main complaint was unilateral lower limb swelling 80 (77.7\%), and pain in 54(52.4\%). Trauma and immobility were in $18(17.5 \%)$ and $19(18.4 \%)$ respectively. The main clinical examination finding was localized swelling in 63(61.2\%), the commonest location being in the lower leg 52(50.5\%). Redness was in 31(30.1\%) while tenderness was demonstrated in $41(39.8 \%)$ cases. The most frequent sonographic finding was deep venous thrombosis (DVT) 39(37.9\%). Lymphadenopathy and oedema were $9(8.7 \%)$ each while varicose veins and cellulitis were $7(6.8 \%)$ and 6(5.8\%) respectively.

Conclusion: The most frequent finding in lower limb swelling was deep venous thrombosis (DVT). 


\section{Introduction:-}

Doppler ultrasound of the lower limb vessels is a well-established technique, which entails demonstration of the arterial and venous system both in morphology and blood flow characteristics. A number of studies have been documented that Doppler sonography has comparable results to venography and arteriography, in diagnosis of various lower limb arterial and venous pathologies. In a study done by Aywak et al (2007), they found that venous sonography had a sensitivity of $88.9 \%$, specificity of $91.8 \%$ and accuracy of $90.9 \%$ in comparison with an invasive, serious side effect laden contrast Venography, which is considered the gold-standard technique for Deep Venous Thrombosis(DVT) diagnosis ${ }^{1}$. Knowledge of the anatomy of the venous and arterial system is paramount in diagnosis. The venous system of the lower limb is divided into the deep and superficial veins located in two main compartments. This anatomy is summarized in Figure 1 below.

Figure 1:-Anatomy of deep venous system (A) and the superficial veins (B)

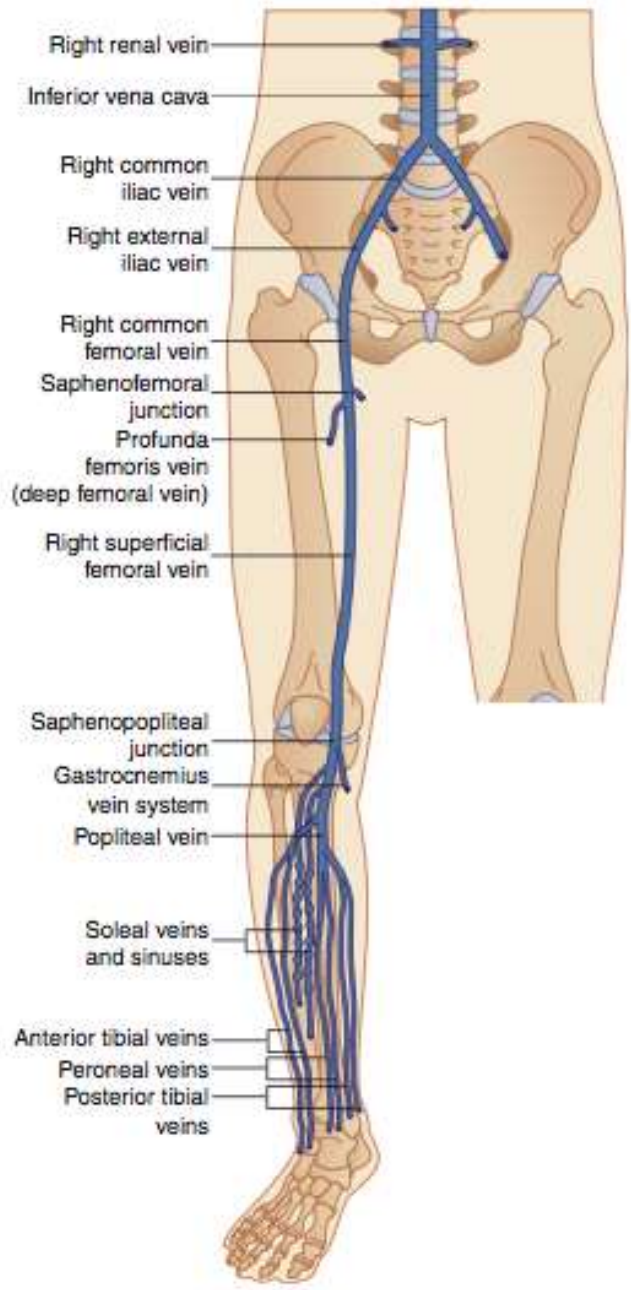

A

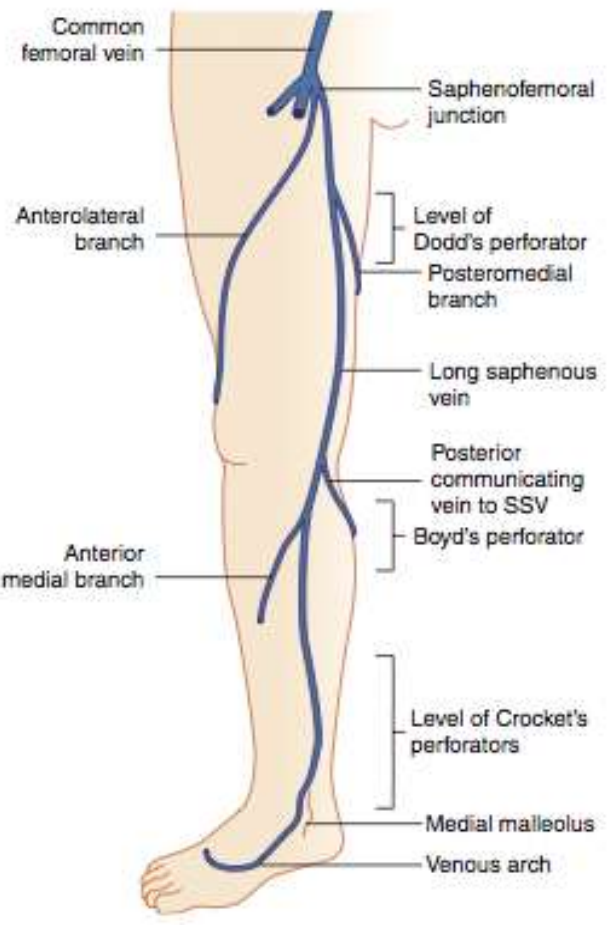

B

Frequently in profiling the patients, clinicians think of deep venous thrombosis (DVT) first in view of the consequences of missing the diagnosis like in fatal pulmonary embolism. Against this background, the bulk of the research narrows down onto the two common etiologies; Cellulitis and Deep venous thrombosis. However nested results from some of the studies bring into light variety of alternative diagnosis $1,2,3$

For instance, a study done in Kenyatta National Hospital, by Aywak et al(2007), on comparison of sonography and venography in diagnosis of DVT, a total of 55 limbs were examined and positive DVT was found in 18 (32.7\%) by venography, and $19(34.5 \%)$ by sonography ${ }^{1}$. Sonography was more useful as alternative diagnoses were found in $18(48.6 \%)$ cases of those who were negative for DVT cases. The alternative diagnoses found during this study were; 10 cases with valvular insufficiency, 4 cases of lymphadenopathy and cellulitis, 2 each for post phlebitis 
syndrome and lymphedema. A similar study done in Uganda by Mangeni et al(2006), where 92 limbs were examined in 86 subjects who were suspected to have DVT, by sonography ${ }^{3}$. In this study, 38 (48\%) cases had DVT, with 2 cases having bilateral DVT. Other diagnoses found were; 5 cases lymphadenopathy, cellulitis in 2 cases. Baker's cyst was found in 1 case and gastrocnemius tumour in 1 case.

However in another study that followed using 886 patients with lower limb swelling over a one year period, DVT was positive in $229(25.8 \%)^{2}$. Of the 657 cases who tested negative for DVT, alternative diagnosis was found in 51 $(11.25 \%)$.

Deep venous thrombosis (DVT) is a common clinical problem that complicates many medical and surgical disorders $^{8}$. It has been shown to affect males more commonly. A study by Bauersachs et al(2010) found the prevalence to be $37 \%(658 / 1778)$ in men as compared to $24.3 \%$ (730/2998) in women ${ }^{9}$. Similar findings were recorded in another study, which surveyed outpatients where prevalence in men was $14 \%$ and women $9.4 \%($ $\mathrm{n}=1838)^{10}$. However some studies have found it to be more in women like in the study in Eritrea, on DVT among intensive care unit, found the ratio of male to female of $0.9: 1^{11}$.

In two different studies, it was found that DVT commonly presents as unilateral swelling ${ }^{12,13}$. In these studies, unilateral and bilateral DVT was present in 31\%(n $=1029)$ and $5 \%(n=159)$ respectively. It has also been shown that clinical manifestation of DVT in both history and physical examination finding is of limited value in its management 14

Sonography for a long time has been used to complement clinical examination in diagnosis of lower limb cellulitis, a life threatening pathological processes ${ }^{6}$. It's prevalence in Africa is largely unknown as data is missing, but is estimated to be $3.7 \%$.

Due to overlapping nature of the clinical presentation of DVT and cellulitis, studies have been done to evaluate presence of coexisting DVT in patients with cellulitis. Maze et al(2013), found only $0.5 \%(\mathrm{n}=200)$ of cellulitis had DVT also ${ }^{16}$.

Sonography is important in confirmation of cellulitis and more so in determining on presence of abscesses ${ }^{7}$ The studies also found that ultrasound provides valuable information in detection of occult abscess, prevention of invasive procedures and guidance for further imaging and consultation ${ }^{6,7}$.

Doppler ultrasound has become the mainstay of lower limb venous assessment in patients with chronic venous insufficiency, which is manifested typically by varicose veins ${ }^{44}$. It is noninvasive and can therefore be repeated, if necessary, without discomfort.

The color Doppler component provides information on the presence, or absence, of blood flow in the relevant segment, which way the blood is moving, and how fast it is moving while the spectral Doppler component allows the measurement of the duration of reflux and other calculations relating to the severity of the valvular dysfunction, including the velocity of reflux and an estimate of the volume of reflux. These findings allow the operator to build an overall picture of the structure and function of the venous segments in the leg being examined ${ }^{17,18}$.

\section{Methods:-}

\section{Study design:-}

This was a cross sectional survey carried out at the Radiology department of Moi Teaching and Referral Hospital (MTRH) Eldoret, Kenya. This is a referral unit for North-western Kenya. The Study population included patients with lower limb swelling, seen at the radiology department of the MTRH. Patients presenting for follow-up examination and those with evidence of other confounding lesions (systemic disease like heart, liver or kidney disease) were excluded from this study.

\section{Sampling technique:-}

Purposive/convenience sampling was used to identify the population with lower limb swelling presenting in the radiology department. Once the participants made an informed decision, they signed the consent form. In case where the participant was a minor (below 18 years of age), both the guardian/parent and the minor were taken 
through the same process of the patient. The patient then assented and the guardian endorsed this decision. Where the minor declined, the guardian complied with patient's wish.

Data was collected from October 2012 to November 2013. All patients presenting for investigations at the radiology department were screened. The ones with lower limb swelling were identified and consent administered. By convenience sampling 103 patients were eventually selected.

This data was then transferred to a computer database. Double entry was used to ensure accuracy of the data. All patient details were kept confidential and data was only available to the investigator and the supervisors via password protection.

\section{Sonographic examination:-}

Both B-mode and M-mode ultrasound with color flow, spectral and power Doppler measurement capabilities were used in all cases. Both linear and curved array transducers with frequencies of at least $5 \mathrm{MHz}$, were used. Ultrasound examination was carried out starting with venous system examination (venous Doppler), arterial system (arterial Doppler) and then soft tissue sonographic examination for those who had focal swelling that needed further characterization.

All venous segments were examined in both longitudinal and transverse axis assessing the following; compressibility, flow pattern on colour Doppler and spectral Doppler. The assessment of venous reflux was performed using valsalva and augmentation maneuvers for proximal and distal areas respectively, with the transducer in a longitudinal plane to the vein. DVT was considered positive if there was absence of normal compressibility, a focal flow void with colour Doppler or absence of visible flow within a segment of a vessel on spectral Doppler. Venous incompetence was considered present if there was significant retrograde flow spontaneous or with distal augmentation on colour Doppler. On spectral Doppler, incompetence was diagnosed when the reflux duration was 1 second or more. The sites that were assessed for venous reflux were; the common Femoral Vein above and below the Saphenofemoral Junction, The Greater Saphenous Vein at its origin, The Popliteal Vein above and below the Lesser saphenous Vein origin and at the origin of the Lesser Saphenous Vein. Varicosities were demonstrated by presence of tortuous dilated elongated vessels in the subcutaneous region, especially along greater or smaller saphenous vein regions.

Finally, sonographic examination included assessment for presence of masses, which were characterized into solid or cystic. Their site, shape, echogenicity, motion on compression and vascularity was also sought to help in sonographic diagnosis.

Subcutaneous tissues were also examined for the presence of oedema that was further characterized into inflammatory oedema as in cellulitis, by use of Doppler to assess for hyperemia and non-inflammatory one that does not present with hyperemia.

\section{Data management and analysis:-}

Data was analyzed using STATA version10. Descriptive statistics such as mean, median were used for continuous data while frequency listings were used for Categorical variables. To assess whether there was any association between categorical variables the chi-squire test was used. In all analysis a p-value less than 0.05 was considered significant.

\section{Ethical considerations:-}

No harm was anticipated and none occurred during the study. There was no material, financial or otherwise inducements. Authority and approval was sought and granted by Institutional Review and Ethics Committee (IREC).

\section{Results:-}

\section{Socio-demographic data:-}

In this study, 1440 patients were reviewed and out of these $148(10.3 \%)$ had lower limb swelling. 109 patients consented to take part in the study. However 6 withdrew their consent for various reasons leaving 103 at the end of the study that were recruited. The sex distribution was skewed towards the female gender comprising of 67 (65\%) with male to female ratio of 1:1.8. The median age was 41 years with age range of 13 to 91years. 


\section{Clinical history:-}

The main presentation was unilateral lower limb swelling $80(77.7 \%)$ and pain in $54(52.4 \%)$ of the cases. Out of the 67 females participants, 5 (7.4\%) were pregnant and 20 (29.4\%) were using contraceptives; 70\% (14/20) of which were hormonal contraception. History of trauma was positive in $18(17.5 \%)$ of the respondents, while prolonged immobility was in 19(18.4\%).

\section{Physical Examination:-}

There was unilateral lower limb swelling $80(77.7 \%)$, predominantly localized in $63(61.2 \%)$ and diffuse in 40 (38.8\%) of the cases. The location of the swelling mainly involved the lower leg 52(50.5\%) followed by the knee representing $32(33.9 \%)$. Colour change (redness) was observed in $31(30.1 \%)$ while tenderness was elicited in $42(39.8 \%)$.

\section{Sonographic findings:-}

Deep venous thrombosis was the commonest diagnosis on Doppler ultrasound in 39(37.9\%) cases followed by Lymphadenopathy and oedema with 9 cases $(8.7 \%)$ in each. Varicose veins were observed in $8(6.8 \%)$ cases and cellulitis $6(5.8 \%)$. In $27(26.2 \%)$ of the study population, their sonographic examination of the vascular and musculoskeletal system was normal. Details of these findings are shown in Figure 2.

Figure 2:- A bar chart showing sonographic Findings

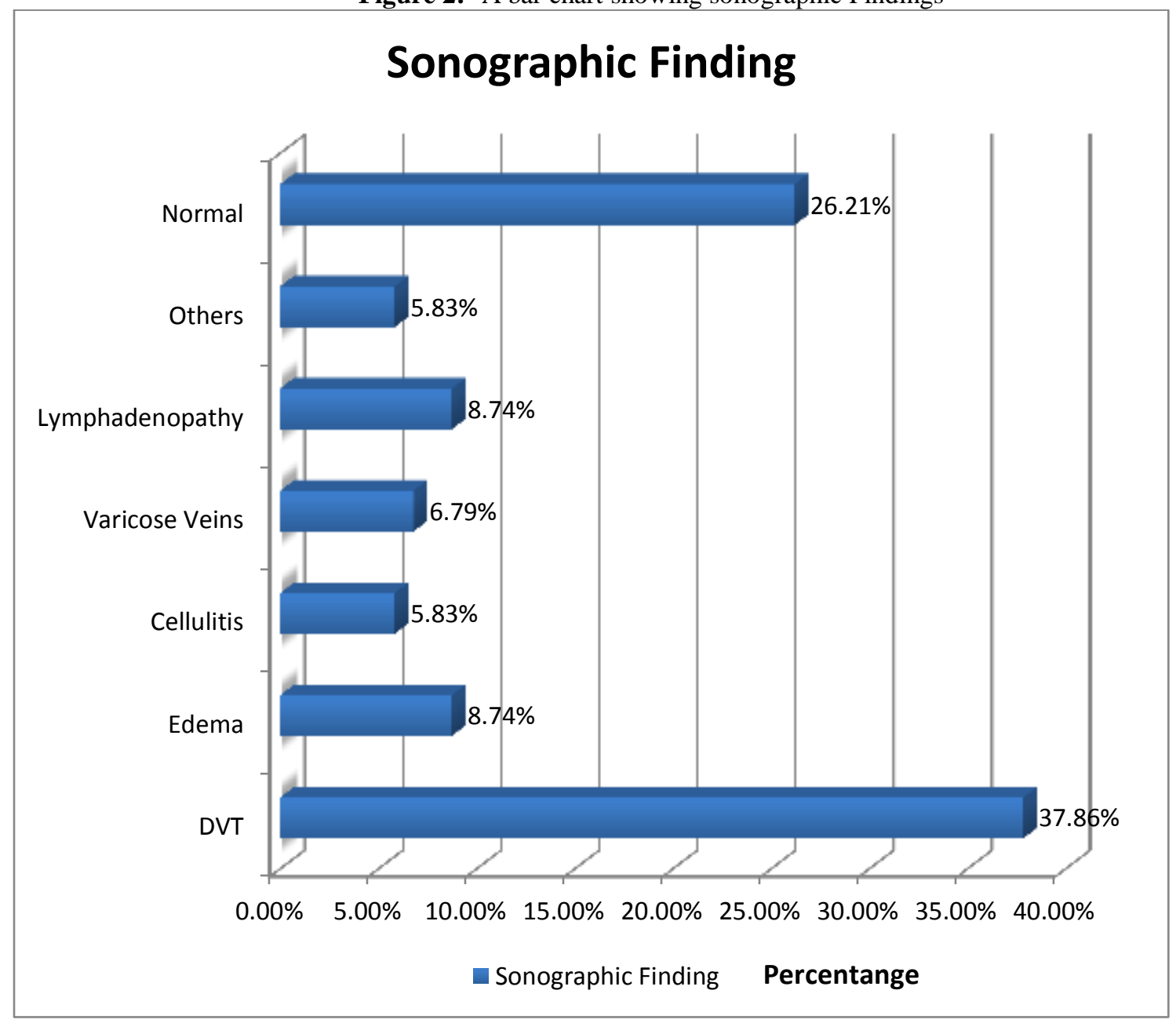

Legend:

DVT: deep venous thrombosis

Others: atherosclerosis, baker's cyst, popliteal aneurysm, soft tissue tumor and pyomyositis Sonographic finding by gender 
In DVT more women were involved 28(71.8\%) than men, however in cellulitis affected men and women equally as shown in figure 3 below.

Figure 3:- A bar chart showing sonographic findings by gender.

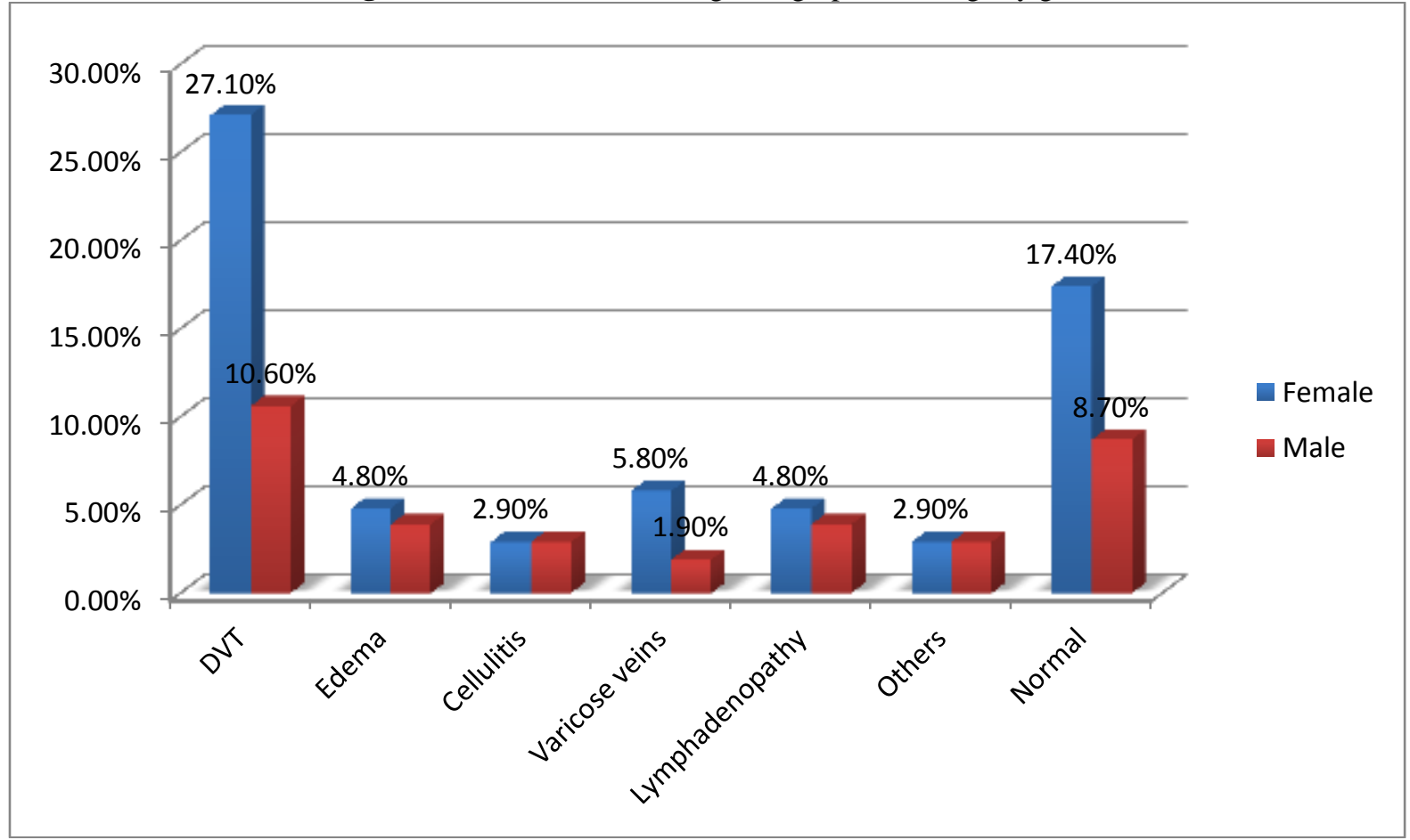

Legend:

DVT: deep venous thrombosis

Others: atherosclerosis, baker's cyst, popliteal aneurysm, soft tissue tumor and pyomyositis.

Sonographic finding in relation to demographics amongst female participants:-

Further analysis showed that DVT was common between the age group of 36-45 years amongst women while cellulitis and varicose veins were common in the above 55years category as detailed in table 1 (NB the percentage is recorded in brackets). Due to the small numbers, it was not possible to ascertain the statistical significance of these findings.

Table 1:- Sonographic findings in various age categories among females

\begin{tabular}{|c|c|c|c|c|c|c|c|}
\hline Variable & $\begin{array}{l}\text { DVT } \\
N=28\end{array}$ & $\begin{array}{l}\text { Edema } \\
N=5\end{array}$ & $\begin{array}{l}\text { Cellulitis } \\
\mathbf{N}=\mathbf{3}\end{array}$ & $\begin{array}{l}\text { Varicose } \\
\text { Veins } \\
\mathbf{N}=\mathbf{6}\end{array}$ & $\begin{array}{l}\text { Lymphadenopathy } \\
\mathrm{N}=5\end{array}$ & $\begin{array}{l}\text { Other } \\
\mathbf{N}=3\end{array}$ & $\begin{array}{l}\text { Normal } \\
N=18\end{array}$ \\
\hline $\begin{array}{l}\text { Age in categories } \\
<20 \text { years } \\
21-35 \text { years } \\
36-45 \text { years } \\
46-55 \text { years } \\
>55 \text { years }\end{array}$ & $\begin{array}{l}7(25.0) \\
5(17.9) \\
8(28.6) \\
4(14.3) \\
4(14.3)\end{array}$ & $\begin{array}{l}0(0.0) \\
1(20.0) \\
0(0.0) \\
0(0.0) \\
4(80.0)\end{array}$ & $\begin{array}{l}0(0.0) \\
0(0.0) \\
2(66.7) \\
0(0.0) \\
1(33.3)\end{array}$ & $\begin{array}{l}0(0.0) \\
0(0.0) \\
1(16.7) \\
2(33.3) \\
3(50.0)\end{array}$ & $\begin{array}{l}1(20.0) \\
0(0.0) \\
1(20.0) \\
1(20.0) \\
2(40.0)\end{array}$ & $\begin{array}{l}0(0.0) \\
1(33.3) \\
0(0.0) \\
1(33.3) \\
1(33.3)\end{array}$ & $\begin{array}{l}3(16.7) \\
5(27.8) \\
6(33.3) \\
1(5.6) \\
3(16.7)\end{array}$ \\
\hline $\begin{array}{l}\text { Occupation } \\
\text { Farmer } \\
\text { Student } \\
\text { Housewife } \\
\text { Employed } \\
\text { Business } \\
\text { Others }\end{array}$ & $\begin{array}{l}5(17.9) \\
5(17.9) \\
9(32.1) \\
5(17.9) \\
2(7.1) \\
2(7.1)\end{array}$ & $\begin{array}{l}1(25.0) \\
0(0.0) \\
2(40.0) \\
0(0.0) \\
0(0.0) \\
2(40.0)\end{array}$ & $\begin{array}{l}0(0.0) \\
0(0.0) \\
2(66.7) \\
1(33.3) \\
0(0.0) \\
0(0.0)\end{array}$ & $\begin{array}{l}0(0.0) \\
0(0.0) \\
2(33.3) \\
2(33.3) \\
0(0.0) \\
2(33.3)\end{array}$ & $\begin{array}{l}1(20.0) \\
1(20.0) \\
2(40.0) \\
1(20.0) \\
0(0.0) \\
0(0.0)\end{array}$ & $\begin{array}{l}1(50.0) \\
0(0.0) \\
0(0.0) \\
1(50.0) \\
0(0.0) \\
1(0.0\end{array}$ & $\begin{array}{l}1(5.6) \\
4(22.2) \\
5(27.8) \\
3(16.7) \\
1(5.6) \\
4(22.2)\end{array}$ \\
\hline
\end{tabular}


Sonographic finding in relation to demographics amongst male participants:-

There was almost a similar presentation of sonographic findings amongst all the age categories and occupation in the male participants. This is shown in table 2 below.

Table 2:-Sonographic findings in various age categories among males

\begin{tabular}{|c|c|c|c|c|c|c|c|}
\hline Variable & $\begin{array}{l}\text { DVT } \\
\mathrm{N}=11\end{array}$ & $\begin{array}{l}\text { Edema } \\
N=4\end{array}$ & $\begin{array}{l}\text { Cellulitis } \\
\mathbf{N}=3\end{array}$ & $\begin{array}{l}\text { Varicose } \\
\text { Veins } \\
\mathrm{N}=\mathbf{2}\end{array}$ & $\begin{array}{l}\text { Lymphadenopathy } \\
\mathrm{N}=4\end{array}$ & $\begin{array}{l}\text { Other } \\
\mathbf{N}=\mathbf{3}\end{array}$ & $\begin{array}{l}\text { Normal } \\
\mathbf{N}=\mathbf{9}\end{array}$ \\
\hline $\begin{array}{l}\text { Age in categories } \\
>20 \text { years } \\
21-35 \text { years } \\
36-45 \text { years } \\
46-55 \text { years } \\
>55 \text { years }\end{array}$ & $\begin{array}{l}2(18.2) \\
3(27.3) \\
2(18.2) \\
2(18.2) \\
2(18.2)\end{array}$ & $\begin{array}{l}1(25.0) \\
1(25.0) \\
0(0.0) \\
1(25.0) \\
1(25.0)\end{array}$ & $\begin{array}{l}1(33.3) \\
0(0.0) \\
1(33.3) \\
0(0.0) \\
1(33.3)\end{array}$ & $\begin{array}{l}0(0.0) \\
0(0.0) \\
0(0.0) \\
1(50.0) \\
1(50.0)\end{array}$ & $\begin{array}{l}1(25.0) \\
0(0.0) \\
2(50.0) \\
0(0.0) \\
1(25.0)\end{array}$ & $\begin{array}{l}0(0.0) \\
0(0.0) \\
1(33.3) \\
0(0.0) \\
2(66.7)\end{array}$ & $\begin{array}{l}0(0.0) \\
2(22.2) \\
2(22.2) \\
3(33.3) \\
1(11.1)\end{array}$ \\
\hline $\begin{array}{l}\text { Occupation } \\
\text { Farmer } \\
\text { Student } \\
\text { Employed } \\
\text { Business } \\
\text { Others }\end{array}$ & $\begin{array}{l}3(27.3) \\
3(27.3) \\
4(36.4) \\
0(0.0) \\
1(9.1)\end{array}$ & $\begin{array}{l}1(25.0) \\
1(25.0) \\
2(50.0) \\
0(0.0) \\
0(0.0)\end{array}$ & $\begin{array}{l}0(0.0) \\
1(33.3) \\
2(66.7) \\
0(0.0) \\
0(0.0)\end{array}$ & $\begin{array}{l}1(50.0) \\
0(0.0) \\
1(50.0) \\
0(0.0) \\
0(0.0)\end{array}$ & $\begin{array}{l}0(0.0) \\
1(25.0) \\
2(50.0) \\
0(0.0) \\
1(25.0)\end{array}$ & $\begin{array}{l}0(0.0) \\
0(0.0) \\
1(33.3) \\
0(0.0) \\
2(66.7)\end{array}$ & $\begin{array}{l}2(22.2) \\
0(0.0) \\
3(33.3) \\
1(11.1) \\
3(33.3)\end{array}$ \\
\hline
\end{tabular}

Associations of sonographic findings with clinical presentation:-

Table 3 below shows the sonographic findings in relation to symptoms and physical examination finding.

Table 3:-Table showing summary of clinical presentation and sonographic findings.

\begin{tabular}{|c|c|c|c|c|c|c|c|}
\hline Clinical parameters & $\begin{array}{l}\text { DVT } \\
\text { N=39 }\end{array}$ & $\begin{array}{l}\text { Edema } \\
\mathrm{N}=9\end{array}$ & $\begin{array}{l}\text { Cellulitis } \\
\mathrm{N}=6\end{array}$ & $\begin{array}{l}\text { Varicose } \\
\text { Veins } \\
\mathrm{N}=\mathbf{8}\end{array}$ & $\begin{array}{l}\text { Lymphadenopathy } \\
\mathrm{N}=9\end{array}$ & $\begin{array}{l}\text { Others } \\
N=6\end{array}$ & $\begin{array}{l}\text { Normal } \\
\mathbf{N}=\mathbf{2 7}\end{array}$ \\
\hline \multicolumn{8}{|l|}{ History } \\
\hline $\begin{array}{l}\text { Swelling } \\
\text { One limb }\end{array}$ & $34(87.2)$ & $5(55.6)$ & $5(83.3)$ & $6(75.0)$ & $5(55.5)$ & $6(100.0)$ & $\begin{array}{l}19 \\
(70.3)\end{array}$ \\
\hline Two limbs & $5(12.8)$ & $4(44.4)$ & $1(16.7)$ & $2(25.0)$ & $3(33.3)$ & $0(0.0)$ & $9(33.3)$ \\
\hline Pain & $34(87.2)$ & $1(11.1)$ & $4(66.7)$ & $4(50.0)$ & $4(44.4)$ & $1(20.0)$ & $5(18.5)$ \\
\hline Pregnancy & $4(10.3)$ & $1(11.1)$ & $0(0.0)$ & $0(0.0)$ & $0(0.0)$ & $0(0.0)$ & $0(0.0)$ \\
\hline Contraceptive & $8(20.5)$ & $1(11.1)$ & $1(16.7)$ & $4(50.0)$ & $0(0.0)$ & $1(50.0)$ & $5(18.5)$ \\
\hline Hormonal contraceptive & $5(12.8)$ & $1(11.1)$ & $1(16.7)$ & $1(12.5)$ & $1(11.1)$ & $5(100.0)$ & $0(0.0)$ \\
\hline Trauma & $8(20.5)$ & $1(11.1)$ & $2(33.4)$ & $1(12.5)$ & $0(0.0)$ & $1(20.0)$ & $5(18.5)$ \\
\hline Immobility & $17(43.6)$ & $0(0.0)$ & $0(0.0)$ & $0(0.0)$ & $0(0.0)$ & $0(0.0)$ & $2(7.4)$ \\
\hline \multicolumn{8}{|l|}{ Physical Exam } \\
\hline Bilateral Swelling & $5(12.5)$ & $4(44.4)$ & $1(16.7)$ & $2(25.0)$ & $3(33.3)$ & $0(0.0)$ & $9(32.1)$ \\
\hline Unilateral swelling & $34(87.2)$ & $5(55.6)$ & $5(83.3)$ & $6(75.0)$ & $4(44.4)$ & $5(100)$ & $\begin{array}{l}19 \\
(67.9)\end{array}$ \\
\hline Diffuse swelling & $23(59.0)$ & $5(55.6)$ & $3(50)$ & $1(12.5)$ & $3(33.3)$ & $0(0.0)$ & $5(17.9)$ \\
\hline Localized & $16(41.0)$ & $4(44.4)$ & $3(50)$ & $6(75.0)$ & $5(55.5)$ & $6(100)$ & $\begin{array}{l}23 \\
(82.1)\end{array}$ \\
\hline Redness & $17(43.6)$ & $1(11.1)$ & $4(66.7)$ & $1(12.5)$ & $4(44.4)$ & $1(16.7)$ & $2(7.7)$ \\
\hline Tenderness & $26(66.7)$ & $1(11.1)$ & $4(66.7)$ & $1(12.5)$ & $4(44.4)$ & $1(16.7)$ & $3(12.5)$ \\
\hline
\end{tabular}




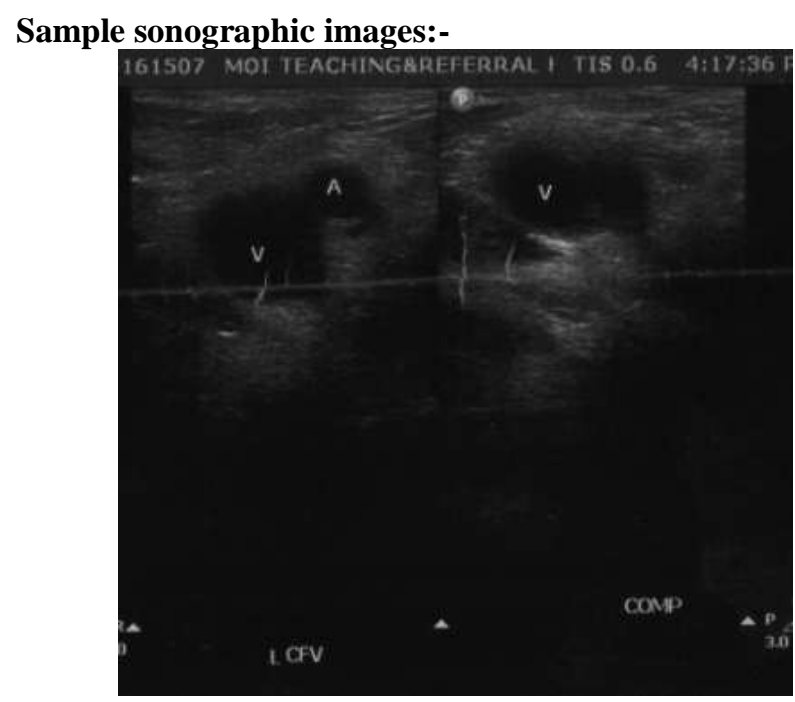

Figure 4:-DVT in 37 yr old male

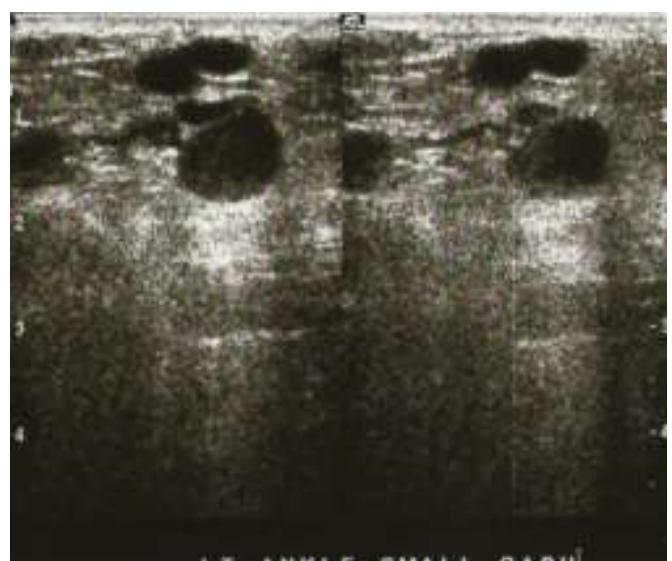

Figure 5:- Varicose veins, 58yr old female

\section{Discussion:-}

103 patients participated in the study; females were a majority 67(65\%) most of whom were housewives $22(21.4 \%)$. This correlates with a study by Bauersachs et al(2010) in which found that females are more $62.8 \%(\mathrm{n}=4776)$ frequently referred for a diagnostic work up as opposed to their male counterparts ${ }^{9}$. The median age of presentation was 41 years.

The main sonographic findings were DVT, Lymphadenopathy, oedema, varicose veins, and cellulitis.

Deep venous thrombosis was the commonest diagnosis $39(37.9 \%)$ in this study. This correlates well with other studies like the Aywak et al (2007) in Kenya, where DVT was found in $32.7 \%(\mathrm{n}=55)$ by venography while it was $34.5 \%(\mathrm{n}=55)$ by sonography ${ }^{1}$. In the Ugandan study, Mangeni et al (2006) found the prevalence was higher at $48 \%$ $(n=92)^{3}$. Borgstede et al (1992) found the prevalence of DVT in $25.8 \%(n=886)^{2}$. Our prevalence is probably higher due to a lower sample or due to different geographical location. The gender specific prevalence of DVT for women in our study was $41.8 \%(n=67)$ while that of males was $30.6 \%(n=36)$. This is in tandem with a study in Eritrea by GoitomHagos et al (2009) that also showed a higher prevalence in women compared to men ${ }^{11}$. However, in our study, most of the affected women were within the reproductive age as the prevalence was $67.8 \%(n=67)$ as compared to $63.6 \%(n=36)$ males for those below 45 years while it was $28.6 \%$ females' verses $36.4 \%$ males for those above 45 years. This could be explained by increased risk factors for women during the reproductive age (pregnancy, hormonal contraceptives and post partum). This prevalence changed for those participants above 45years to more males verses females (36.5\% verses $28.6 \%)$. Consistent with our findings, Bauersachs and colleagues who did a similar study among patients with suspected DVT found that the prevalence was higher in males than in women $37 \%(n=2998)$ vs.24.3\% $(n=1778)$ and that male sex was a predictor of presence of venous thrombosis independently of signs and risk factors for the same ${ }^{9}$. Andreou et al (2008)found same results but lower prevalence, that men were more affected at $14.4 \%(\mathrm{n}=1838)$ as compared to women at $9.4 \%(\mathrm{n}=1838)^{10}$. This study however used clinical indicators for DVT, unlike our study, which confirmed the same with ultrasound.

Unilateral presentation of DVT was encountered more in 87.2\% (34/39) comparing favorably with a retrospective study by Lemech et al (2004) that found 69\% $(\mathrm{n}=1029){ }^{12}$ but differed in the bilateral presentation of the symptoms in $31 \%(n=1029)$ unlike in our study where we found only $12.8 \%(5 / 39)$. This could be as a result of the higher number recruited in their study 1029 verses 103 participants and their study only looked at cases with DVT specifically. However a study by Garcia et al (2001)looking at a contralateral asymptomatic limb duplex scan showed a lower figure of $5 \%(n=159)^{13}$, which is lower than our prevalence of $12.8 \%$ despite looking at the a highly selected population.

Lymphadenopathy and edema were the second most frequent diagnoses in this study presented by a prevalence of $8.7 \%(9 / 103)$ in each. These two findings were non-specific as there are a number of pathologies that could cause 
these features. For instance non- inflammatory oedema could be as a result of lymphatic disorders (lymphedema) that requires diagnosis by lymphoscintigraphy or due to a systemic condition like renal, liver and heart diseases that were beyond the scope of this study. This correlates well with a study by Kotaro and Noriyasu(2013) who correlated ultrasound finding in patients with lymphedema diagnosed by lymphoscintigraphy ${ }^{5}$. They found that ultrasound was suboptimal in diagnosis and may require special transducer of between 50-100 MHz. A recommendation for further diagnostic studies was therefore recommended, and these included suggestions for lymph node biopsy and lymphoscintigraphy.

Varicose veins being typical manifestation of chronic venous insufficiency were identified in 7(6.7\%) cases similar to the San Valentino study in Italy, that found a prevalence of $7 \%(n=30,000){ }^{4,21}$. The prevalence was $9 \%(6 / 67)$ among women while it occurred in 5.6\%(2/36) of the male participants in our study. That more women were affected also resonated with the San Valentino study as well as The Framingham study ${ }^{21,22}$. This value is however lower as compared to the Tempere Varicose vein study in Finland where the prevalence was $7 \%$ among the male respondents against $25 \%$ in women. In the Tempere Varicose vein study, they used clinical presentation only unlike in our study where we used both clinical and ultrasound to confirm the presence of the same. Of value, our study found that most of those affected were above 45 years of age $87.5 \%(n=8)$ with none below the age of 35 years. This is in agreement with other studies showing that the prevalence of varicose veins seems to increase with increasing age and that it is more prevalent in women $4,18,22$

However our results differ significantly with those found in a population based study done in France that found a prevalence of $50 \%(\mathrm{n}=8000)$ in women and presentation being more common in females ${ }^{20}$. This literature too concurs with others studies that show that the prevalence of varicose veins ranges from $<1 \%$ to $73 \%$ in females and $2 \%$ to $56 \%$ in males ${ }^{19}$. The differences could be attributed to differences in population characteristics, as the condition is less prevalent in developing countries. Accuracy in application of diagnostic criteria, and the quality and availability of medical diagnostic and treatment resources could be another contributor to the differences.

Few studies have documented the prevalence of cellulitis, our study found $6(5.8 \%)$ cases and it affected males and females equally with no variation in presentation by age groups. The commonest presentation was that of unilateral swelling $83.6 \%(n=6)$, pain, redness and tenderness in 66\%. A study done by Mc Namara and his colleagues found a lower incidence rate of $3.7 \%{ }^{15}$. This was a population-based study where they set out to find incidence of lower limb cellulitis unlike our hospital-based study. The highly selective population of participants in our study may have resulted in a higher prevalence.

The prevalence of peripheral artery disease in this study was 3(2.9\%). These were represented by 2 cases of atherosclerosis $(1.9 \%)$ and one case of a popliteal artery aneurysm (1\%). These findings were mainly observed in males. These findings correlate well with other studies that have documented that worldwide prevalence is between 3- $12 \%{ }^{24,25,26}$.

The other lesions encountered were: Baker's cyst, soft tissue mass and pyomyositis that were represented by one case each. The prevalence of Baker's cyst in our study was $<1 \%$, which resonates well with the study done in Uganda, which also recorded 1 case of baker's cyst ${ }^{3}$. It is however lower than the quoted literature that shows 5 $32 \%$ and was found in an adult ${ }^{26}$. This is probably low because there were no children below the peak age of $5-7$ years that were recruited in the study.

\section{Conclusions:-}

Deep venous thrombosis is the commonest sonographic finding in lower limb swelling and it affects more women in reproductive age group.

\section{References:-}

1. Aywak AA, Masesa JV. Comparison of sonography with venography in the diagnosis of deep venous thrombosis. East Afr Med J. 2007 Jul; 84(7): 304-11.

2. Borgstede J.P and Claggett G. E. Types, frequency and significance of alternative diagnoses found during duplex Doppler venous examination of the lower extremities. Ultrasound. Med.1992, 11: 85-86.

3. Mangeni F, Kawooya M G, et al.Sonography and risk factors for lower limb deep venous thrombosis at Mulago hospital, Uganda. East Afr med J, 2006; 83:443-449. 
4. TiinaAhti et al, Risk factors of varicose veins. TempereenYliopistopainoOy - JuvenesPrint.Tampere 2010.

5. Kotaro S, Noriyasu M. Significance of ultrasound examination of skin and subcutaneous tissue in secondary lower extremity lymphedema. Ann Vasc Dis:2013; 6(2):180-188

6. Vivek S. Tayal, Nael H.et al. The effect of soft tissue ultrasound on the management of cellulitis in the Emergency department. Academic Emergency Medicine 2006;13: 384- 388

7. S. Adhikari, et al.Sonography First for subcutaneous abscess and cellulitis evaluation. $J$ Ultrasound Med October 2012; 31(10): 1509-1512

8. Ginsberg J S. Management of venous thromboembolism. N Engl J Med 1996; 335:1816 1828

9. Bauersachs RM, et al, Impact of gender on clinical presentation and diagnosis of deep vein thrombosis. Thromb. Haemost. 2010 Apr;103(4)

10. AndreouER,et al. Differences in clinical presentation of deep vein thrombosis in men and women. $J$ ThrombHaemost. 2008 oct;6(10): 1713-9

11. GoitomHagos, M.D Lower Extremity Deep Vein Thrombosis among Intensive Care Patients in Orotta National Referral Hospital, Journal of Eritrea Medical Association. 2009;4:1

12. Lemech $\mathbf{M} \mathbf{D}$ et al. Is bilateral duplex scanning necessary in patients with symptoms of deep venous thrombosis? ANZ J Surg 2004 oct; 74 (10) 847-51

13. Garcia $\mathbf{N} \mathbf{D}$ et al. Is bilateral ultrasound scanning of the legs necessary for patients with unilateral symptoms of deep vein thrombosis? J VascSurg 2001 Nov; 34 (5): 792-7

14. Oudega R, Moons KG, Hoes AW. Limited value of patient history and physical examination in diagnosing deep vein thrombosis in primary care. FamPract 2005; 22:86-91.

15. Mc Namara DR, et al, Incidence of lower extremity cellulitis; a population based study in Olmsted County, Minnesota. Mayo clinic Proc. 2007 Jul;82(7):817-21.

16. Maze MJ et al. Prevalence of concurrent deep venous thrombosis in patients with lowerlimb cellulitis: a prospective cohort study. BMC infectious Disease. 2013 13; 141

17. Allan P.L, Role of ultrasound in the Assessment of Chronic Venous Insufficiency, Ultrasound Quarterly 2001; 17: 3-10.

18. ACR,AIUM and SRU, Practice Guideline for the Performance of Peripheral Venous Ultrasound Examinations J Ultrasound Med January 1, 2011; 30(1): 143-150

19. Jennifer L. Beebe-Dimmer MPH, PhD, John R. Pfeifer MD, et al. The epidemiology of chronic venous insufficiency and varicose veins. Annals of Epidemiology, March 2005, vol 15(3): 175-184

20. Patrick H, Carpenter MD, et al. Prevalence, risk factors and clinical patterns of chronic venous disorders of lower limb: A population based study in France. Journal of Vascular surgery Octber 2004, Vol 40(4): 650-659

21. Cesarone M. R., Belcano A. N.,Nicolaides A. N.,et al. 'Real' Epidemiology of varicose veins and chronic venous disease: The San Valentino vascular screening project. Angiology; 53: 119-130.

22. Brand FN, Dannenberg AL, Abbott RD, et al. The epidemiology of varicose veins: the Framingham study. Am J Prev Med. 1988; 4:96-1

23. Norgren L, Hiatt WR, Dormandy JA et al. Intersociety consensus for the management of peripheral arterial disease (TASC II) J VascSurg 2007; 45suppl S: S5.

24. Olin JW Sealove BA. Peripheral artery disease: current insights into the disease and its diagnosis and management. Mayo clinproc 2010; 85:678

25. Novo S. Classification, epidemiology, risk factors and natural history of peripheral arterial disease. Diabetes ObesMetab 2002;4Suppl 2: S1

26. Gristina AG, Wilson PD. Popliteal cysts on adults and children. A Review of 90 cases. Arch Surg 1964;88:357 